\title{
Organizational structures of mining companies: composition and development
}

\author{
Sergei Yaschenko*, Vladimir Polyakov, and Tatiana Sabitova \\ Volgograd State Technical University, 400074 Volgograd, Russia
}

\begin{abstract}
The organizational structures of large companies from the same industry are typical. But the geographic, economic and political conditions of activity impose some particularities on them. In-depth analysis of the organizational structure allows us to notice these external factors and identify the internal characteristics and management model. The paper studies the organizational structures of large potash mining companies. The criteria for identifying the structural divisions of companies are determined, conclusions are drawn about the most typical organizational structures in the industry, the most likely ways of developing the corresponding management models are considered.
\end{abstract}

\section{Introduction}

Effective management of the property complexes of industrial enterprises is the key to the successful economic activity of any company, especially in the capital-intensive mining industry. The constant trend of capital expansion can lead to negative economies of scale, consisting in a significant increase in unproductive costs, insufficient efficiency of top and operational management, an increase in the tax burden, etc. To partially prevent such negative manifestations of the growth of industrial production, one should use scientifically grounded principles of enterprise management, taking into account the specifics of production activities, current restrictions, experience of such work and expected results.

\section{Methods}

To achieve the purpose of the study, the following scientific methods are used: a comparative analysis, a retrospective analysis, a method for identifying cause-effect relationships, analysis of regulatory documentation, system analysis, forecasting, a practice-oriented approach.

As the current society is with millions of organizations and institutions, it is required that they are organized in the form of limited configurations [1]. An enterprise is not a simple collection of disparate things and arbitrarily chosen obligations, but a single territorialproperty complex necessary for entrepreneurial activity. Since the property is the operational base of the production processes of the enterprise, the structure of the enterprise is a reflection of the organizational structure, showing the distribution of property between these divisions [2].

\footnotetext{
* Corresponding author: elto@mail.ru
} 
Organizational structure is defined as the total of the ways in which the work is divided into different tasks, achieving coordination [3]. The organizational model of enterprise management includes the characteristic features of the management of the property complex, the principles of formation, delegation of powers and the vesting of responsibility. Organizational structures describe the relationship between individual organizational units in a company in order to perform managerial and administrative functions (planning, organization, motivation and control), as well as executive functions (processes). The organizational structure of management of an industrial enterprise is a set of specialized functional units interconnected in the process of substantiation, development, adoption and implementation of managerial decisions within the framework of a single territorial-property complex. The basic idea of developing the organizational structures of industrial enterprises is the division of tasks in such a way as to ensure the effective functioning of the territorialproperty complex of the company and the fulfillment of its tasks.

To improve performance indicators, the possibility of unifying the management model is equally important [4]. Effective management of the property complex within the framework of the organizational interaction of divisions of any company can be described by the following four characteristics: specialization, hierarchy, centralization and formalization [5].

Specialization is a clear division of human labor according to its forms and the allocation in this regard of special structural units in which labor activity is carried out in a similar way. In these organizational units, the activities of employees are concentrated on narrow areas of administration and its strategic development. Specialization increases efficiency, simplifies communication and decision-making, and facilitates the formalization process. In addition, it leads to the identification of the most important, critical areas of the functioning and thereby helps to adequately design a management model.

The hierarchy of management creates a normative classification that establishes links between leadership, dependence or subordination. Each hierarchically structured system has both structural and functional differentiation, i.e. each level specializes in performing a certain range of functions. An efficiently built hierarchy of management leads to a high clarity of the system, the concentration by the head the management of the entire set of specific processes, the severity of responsibility and the quick reaction of executive departments to direct instructions.

The centralization of management ensures the concentration of administrative actions and power in one specific place, a governing body or in the hands of one person. The right to make the most important decisions remains with the highest levels of management. Centralization improves control and coordination of management process, reduces the number and scale of erroneous decisions. Strong centralized management avoids a situation in which some elements of the territorial-property complex grow and develop at the expense of others or to the detriment of the organization as a whole.

Formalization of management makes it possible to represent all business processes occurring at this level in the formal system and is aimed at eliminating chaos. Formalization also characterizes the set of tools used in the management which make it possible to systematize and methodologically clarify the composition and features of the functioning of the property complex. During innovation exploitation, when production, trade, and financial tasks of a repetitive and routine nature are performed, the features of the organizational structure need to be more bureaucratic to ensure high efficiency [6]. Software products play a significant role in the process of formalizing the management. However, implementing new information systems in an organization implies the risk that the new system is not really used and decoupled from daily decision making [7].

So there is a need to determine the optimal organizational structure of companies in different industries, taking into account the above principles. 


\section{Results}

The optimal structure corresponds to the existing needs, has the ability to quickly and adequately respond to their changes, and relies on the rational use of resources [8]. Building an organizational structure adequate to the tasks of an enterprise is an important aspect of effective management. The main criterion for determining the organizational structure of a company is segmentation at the senior management level (senior officials, vice presidents), which is individual for different types of organizations. But all of these principles are universal and suitable for large and small companies.

We are especially interested in the experience of large mining companies. Linear structures in this industry are seldom to use due to the complexities of managing an extensive network of divisions of a large enterprise. A functional management structure is standard for small miners with one or two mines in a small area. In the case of medium-sized mining companies and large corporations, the functional structure is also the industry standard. The organizational structures of global mining companies, while formally often divisional, provide a variety of models at many levels of management [9].

Within the framework of this work, the organizational structures of the world's largest mining companies [10] were investigated in order to determine the similarities and differences, to identify special principles of their constructing. Potash companies were preferred.

The largest potash mining company is China's QSL Industry (Sinochem Group) (fig.1). A special role in its functioning is played by a developed strategic management system, which includes a group of top managers who head certain areas of activity or administration remotely from production sites.

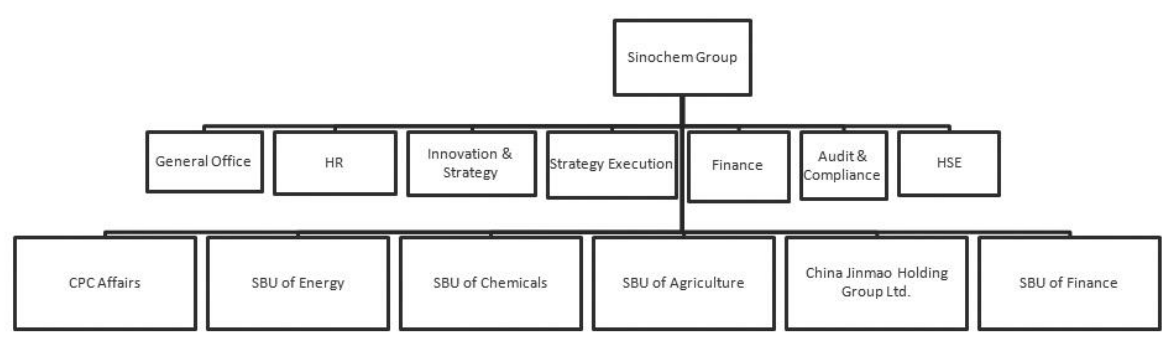

Fig. 1. Organizational structure of Sinochem Group

Under the leadership of the group, several top management divisions carry out the dayto-day management, incl. personnel, financial, audit and compliance, strategy execution, etc. Moreover, the versatility of these subsidiary units is characteristic for all enterprises of the group. Further disclosure of the organizational structure of the group indicates the divisional principle of its construction, the criterion of which is the produced product and general business processes.

Allocation of subdivisions in the organizational structure according to the manufactured product in the framework of the top management is characteristic for the world potash market leader the Canadian Nutrien Ltd. (fig.2). 


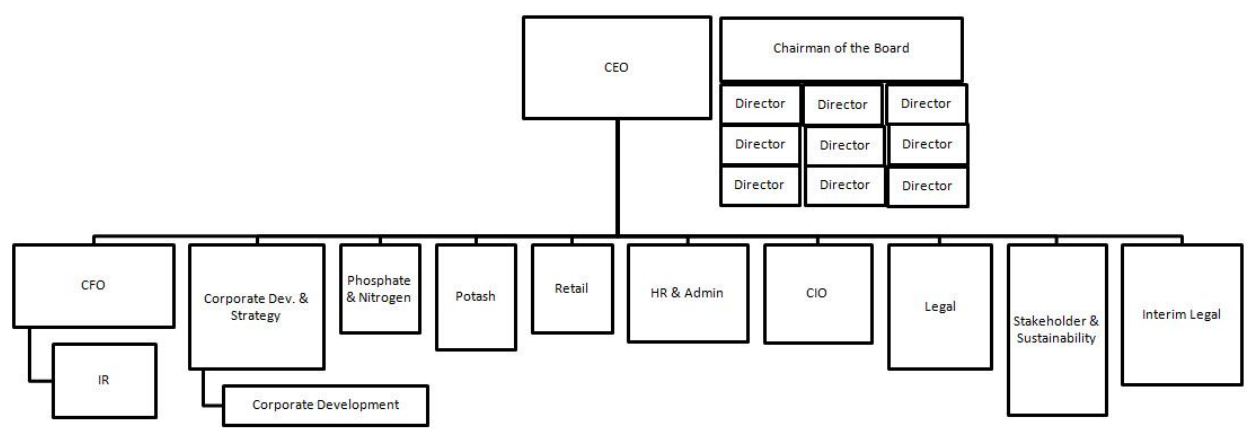

Fig. 2. Organizational structure of Nutrien Ltd.

Within the framework of the group's top management divisions are distinguished that carry out the production of phosphates, nitrogen, potash. The organizational structure, therefore, is presented as a combination of the linear-functional type at the level of senior management and the divisional principle at the level of the production.

The Mosaic Company (USA) combines the principles of forming the highest level of management within the organizational structure of the management (fig.3).

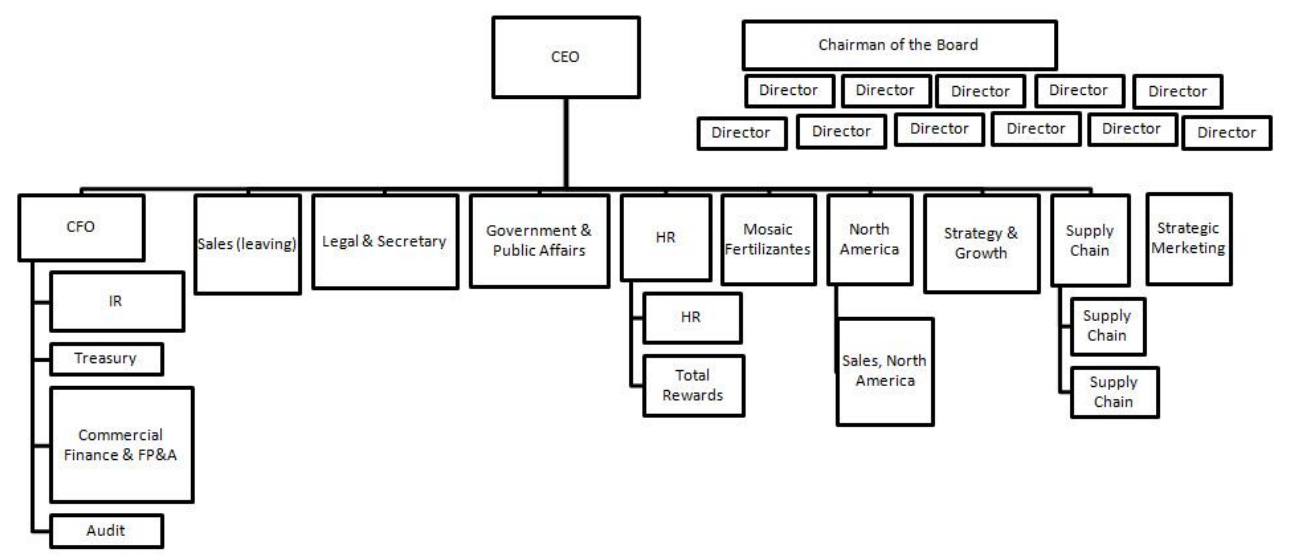

Fig. 3. Organizational structure of The Mosaic Company.

Among the divisions (subsidiaries) of the company, you can find a special one dealing with the production of fertilizers (Mosaic Fertilizers) so the principle of the produced product is used. And at the same time, there is a division focused on sales exclusively on the North American continent (North America dept.). This indicates the use of a geographical principle of product distribution.

Mixed organizational structures are typical for multinational companies. Allocation of separate subdivisions on the basis of a geographic principle is quite common. Intrepid Potash, Inc. is another example (fig.4). 


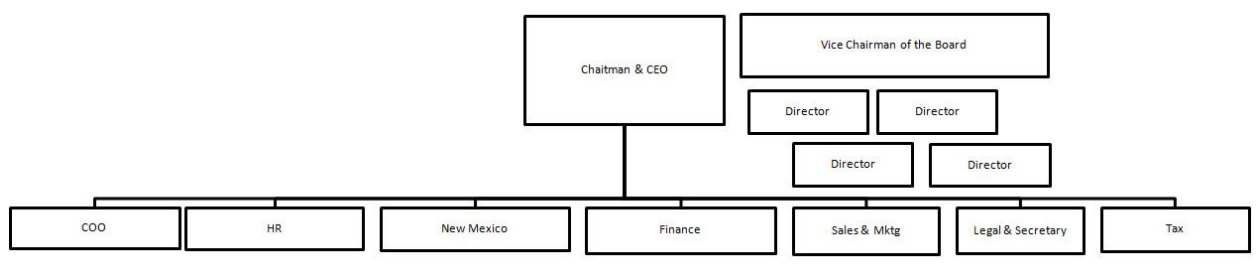

Fig. 4. Organizational structure of Intrepid Potash, Inc.

The division in New Mexico (USA) is represented in a special way. The organizational structure of the head structure of the company has features of a linear-functional type with the centralization of top management.

The separation of company divisions on the basis of the project they are implementing also takes place in the mining industry. An example is the $\mathrm{K}+\mathrm{S}$ Potash Canada General Partnership, which organizational structure (fig.5) has a separate unit responsible for the implementation of strategic projects for production and technology (Capital Projects \& Technology dept.).

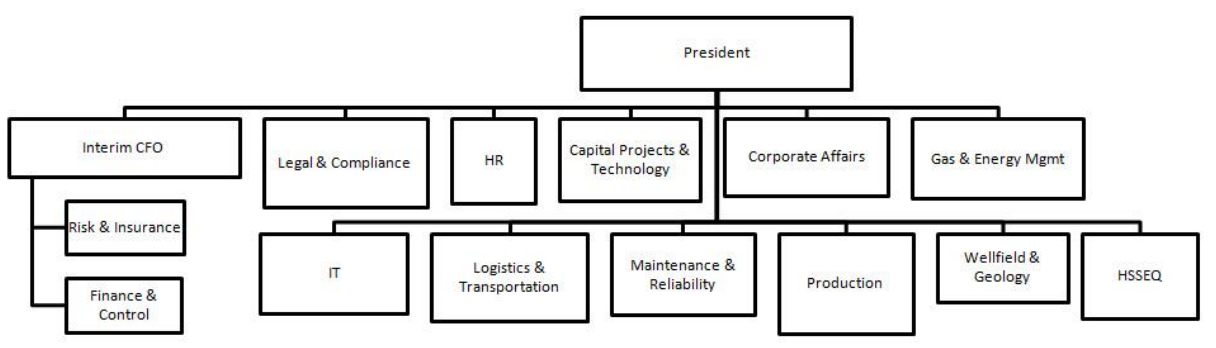

Fig. 5. Organizational structure of $\mathrm{K}+\mathrm{S}$ Potash Canada General Partnership.

The structure of management of this company attracts attention by the concentration of management not at the top of the group, but directly at the level of production and business processes of the operational segment.

The organizational structure of the top management of the EuroChem Group is a linearfunctional model with elements of a divisional type of management (fig.6). The divisions are separated according to ongoing projects (within subsidiaries), by types of production activities (fertilizers, mining, capital-intensive projects) and business processes (development, personnel, sales).

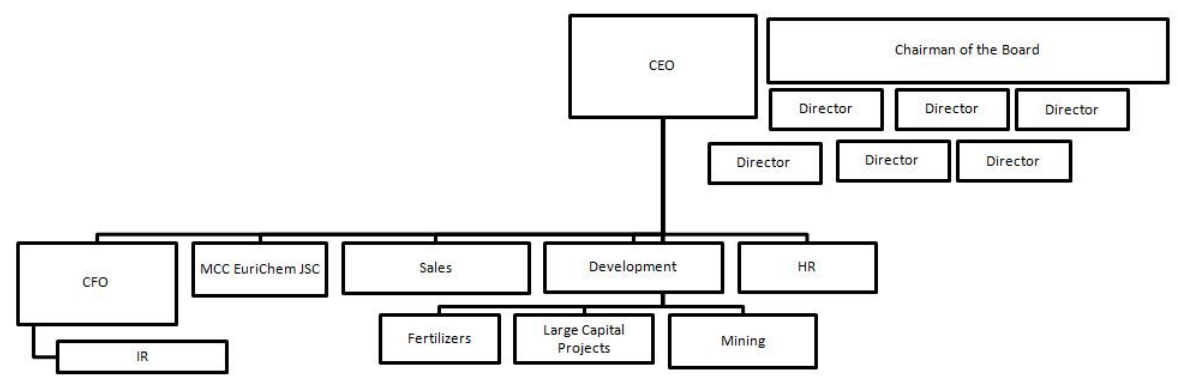

Fig. 6. Organizational structure of EuroChem Group.

The most extensive structure of production units, formed according to several principles on the basis of a mixed organizational model, can be observed in Belaruskali, JSC (fig.7). 


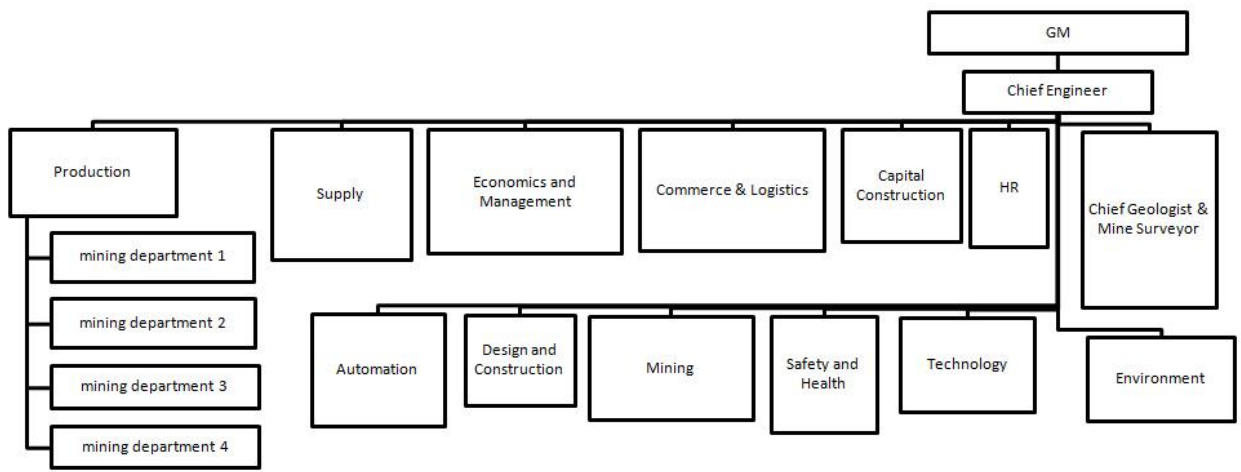

Fig. 7. Organizational structure of Belaruskali, JSC.

The organizational structure is formed according to the linear-functional and divisional principles at the same time. The allocation of four production sites (mining administrations) within one enterprise is characteristic of the divisional structure, while the ramified management, support and service apparatus forms a linear functional superstructure. There is an obvious bias towards administrative and production processes so the number of technical services directly related to the main production activities of the enterprise is much higher than their number in the above examples.

\section{Discussion}

Based on the results of the analysis of the organizational structures existing at the considered enterprises, it was determined that the following principles are most widely applied:

- project management - involves the creation of special structures or subsidiaries to coordinate work on each production or investment project, ensuring the entire life cycle;

- management by geographic regions - well adapted to the regional peculiarities of production and sales, it allows to increase the efficiency of foreign divisions, attracts investments, is identical to the project management with national characteristics;

- organization by product (divisional) - the company's field of activity is divided into a number of industries, each of which is associated with the sale of products of the same group or serving the same customers;

- mixed - used in the vast majority of cases in large companies due to the complexity of the production process, the specifics of legislation and management, safety requirements for various activities, etc. The application of the mixed principle of building the organizational structure and its use in the management model makes this process more maneuverable, able to adequately respond to changes in the internal and external environment of the enterprise. All considered organizational structures in this work had signs of a mixed formation principle, which proves its effectiveness for the global mining industry.

The organizational structure and territorial-property complex of a large company operating on a global scale must correspond to the current market and technological situation, but at the same time be able to progress along with world practice and trends in the development of business structures. The experience for many host governments in recent times has been that as company earnings have grown dramatically, the growth of their own revenues from the extractive industries has lagged well behind and fallen as a proportion of overall profitability [11]. High-tech enterprises should also be able to explore innovations and combine the optimal performance of operational units with the exploitation of innovations [12]. The strategic level of management implies the presence of an integrated 
system for setting and implementing strategic goals for the development of the functioning of the property complex, based on predicting the environment and developing ways to adapt to its changes, as well as impact on it [13].

\section{Conclusion}

The organizational structure in the future will be characterized by four main differences from today's pyramid-based models. The main trend will be a decrease in the number of management levels. Organizations of the future will be characterized by the delegation of decision-making authority to lower levels, where the factors influencing the restructuring are most evident. At the same time, the total number of levels of government will decrease due to significant decentralization. The network character must become dominant in organizational structures. Networked organizations place minimal emphasis on centralized coordination. The units that are part of the organizational network are coordinated by themselves and respond to environmental changes, if necessary. Organizational change requires the redistribution of scarce resources to the change project and includes such activities as employee training, effective IT support, and support from the administration's top management [14].

CEOs should continually monitor and improve the alignment of the strategy and organizational structure by implementing the necessary changes in the dynamic perspective, as well as reconcile tensions arising between exploration and exploitation activities [15]. The construction and transformation of the organizational structure leads to the separation of the property complex, the distribution of responsibility and departmental structure. In this regard, the issue of preserving production and technological links between the divided parts of the property complex becomes urgent. Property management consists in a continuous purposeful impact on property objects in order to maintain their performance, bring their condition to the requirements of production and the modern technical level, renovate and retrofit, ensure the greatest return from their functioning, and reduce irrational costs during operation.

\section{References}

1. G.A. Ahmady, M. Mehrpour, A. Nikooravesh, Procedia - Social and Behavioral Sciences, Vol. 230, 455 (2016). DOI:10.1016/j.sbspro.2016.09.057

2. V.A. Kiseleva, P.V. Ovchinnikova, SUSU Bulletin Series "Economics and Management", 22, 117 (2012)

3. H. Mintzberg, The structuring of organizations: A synthesis of the research, PrenticeHall, Englewood Cliffs, NJ (1979)

4. A.I. Pirogov, N.S. Svechnikov, Economic and socio-humanitarian studies, 3(19), 47 (2018). DOI: 10.24151/2409-1073-2018-3-47-56

5. D.S. Pugh, D.J. Hickson, C.R. Hinings, C. Turner, Dimensions of organization structure, Administrative Science Quarterly 13(1), 65 (1968)

6. R.L. Daft, Understanding the theory and design of organizations, Mason, $\mathrm{OH}$ : Thomson South-Western Mason, (2007)

7. J. Christiaens, J. Rommel, Financial Accountability \& Management 24(1), 59 (2008)

8. V.G. Polyakov, S.O. Yaschenko, Bulletin of the Volgograd state university. Series 10: Innovative activities 1(8), 5 (2013)

9. J. Kudełko, Gospodarka Surowcami Mineralnymi - Mineral Resources Management 32(4), 157 (2016) 
10. T. Lot, The organizational charts of the 75,000 largest corporations, The Official Board, available at: www.theofficialboard.com (2021)

11. A.R. Vining, M.A. Moore, Resources Policym 54, 71 (2017). 10.1016/j.resourpol.2017.09.002

12. J. Bessant, High involvement innovation, Chichester: John Wiley \& Sons Ltd. (2003)

13. K.G. Kuleshova, A.V. Lobacheva, The property complex management system, University Management: Practice and Analysis, 104(4), 129 (2016)

14. H.G. Ridder, H.J. Bruns, F. Spier, Public Management Review 8(1), 87 (2006)

15. A. Zakrzewska-Bielawska, J. of Management\&Organization, 22(5), 599 (2016). DOI:10.1017/jmo.2015.55 